\title{
Research in the supporting sciences
}

\section{Linguistic theory}

\author{
90-225 Andersen, Paul Kent ( $U$. of Bielefield, FRG). Remarks on the origin of \\ the term 'passive'. Lingua (Amsterdam), 79, 1 (1989), 1-16.
}

Our modern linguistic term 'passive' derives via Latin 'passivum' from the Greek grammatical term 'páthos'. In the Greek grammatical tradition (and in particular that of Dionysius Thrax) unequivocal reference is made to three distinct terms subsumed under the heading 'diathesis', i.e. the terms generally translated as 'active', 'middle' and 'passive'. Likewise, in traditional descriptions of Classical Greek grammar reference is made to distinct morphological categories for the 'active', 'middle' and 'passive'. The purpose of the present paper is to show first of all that there is no empirical evidence for the existence of a morphological category in the Classical Greek language for the 'passive' as distinct from that of the 'middle'. Moreover, a closer look at the Greek grammatical terms reveals the fact that the term pathos (generally translated as 'passive') does not in fact refer to a distinct morphological category for the 'passive', but rather to the distinct morphological category 'middle'. The conclusions reached in this paper therefore question the very existence of a typologically valid prototypical/ universal morphological category for the 'passive'.

90-226 Claverie, B. (U. of Bordeaux 2). Apprentissage et plasticité cérébrale. [Learning and the plasticity of the brain.] Revue de Phonétique Appliquée (Mons. Belgium), 90 (1989), 17-34.

The influence and structuring role of learning and of the influence of the environment on the organisation and plasticity of the brain are described. The latter is presented here in its fundamental neurobiological

dimension, more precisely on the level of the neocortex, the higher functions situated there, cognitive processes, and language.

\section{Sociolinguistics}

90-227 Cohen, Andrew D. (Hebrew U. of Jerusalem). Attrition in the productive lexicon of two Portuguese third language speakers. Studies in Second Language Acquisition (Bloomington, Ind), 11, 2 (1989), 135-49.

This study investigates loss of productive vocabulary in oral language, specifically in Portuguese as a third language for two English-Hebrew bilingual children, ages 9 and 13. The study investigated the lexical loss in Portuguese storytelling behaviour after one, three and nine months of discontinued contact with the language. The analysis focused on the nature of the attrited productive lexicon, lexical production strategies used to compensate for forgotten vocabulary, and lexical retrieval processes during storytelling in Portuguese and in the children's two dominant languages.

A significant decrease was found in the total number of words produced in the Portuguese stories of the two children after nine months, both in comparison to word total in earlier months and in comparison to total words in English and Hebrew stories. There was greater attrition in the case of the younger subject after nine months than in that of his older sister. He used a more limited number of different words, as well as fewer and shorter T-units per utterance, which was not the case with regard to his sister. He also attrited proportionately more nouns than words from other word classes.

The subjects used at least six lexical production strategies in order to compensate for forgotten words - two of them L1-based (borrowing and foreignising), and four of them intralingual (the use of a general word, approximation, circumlocution, and word abandonment). Their data also provided evidence of lexical retrieval processes. Examples of lexical production strategies and lexical retrieval processes are given. 
90-228 Cummins, Jim (Ontario Institute for Studies in Education). Language and literacy acquisition in bilingual contexts. Journal of Multilingual and Multicultural Development (Clevedon, Avon), 10, 1 (1989), 17-31.

Studies in the period 1920-60 suggested that bilingualism had negative effects on educational attainment, but this is now widely thought to be an incorrect conclusion due to a focus on children whose first language was disfavoured by society. More recent research from all over the world suggests that bilingualism, and bilingual education, generally have positive effects - a high level of fluency can be achieved in the second language without reduced performance in the first, whilst the metalinguistic and general cognitive development of the bilingually educated equals or exceeds that of monolinguals.
It is essential, however, that children be allowed to use the second language in class for genuine communicative interaction rather than just learning it as a subject by teacher-centred methods. Public support for bilingualism and the allocation of substantial resources are also necessary. The failure of bilingual education in Ireland and Frisia (Friesland, Netherlands) may be related to neglect of these considerations. The author proposes, particularly for the Frisian situation, a model of research-based language planning along lines successful in Canada and elsewhere.

90-229 De Bot, Kees (U. of Nijmegen) and Clyne, Michael (Monash U.). Language reversion revisited. Studies in Second Language Acquisition (Bloomington, Ind), 11, 2 (1989), 167-77.

In the 1970 s, Clyne conducted linguistic research on German-English and Dutch-English bilinguals in Australia. In the course of the study, he found evidence for second language attrition and first language reversion among his elderly informants. In 1987 , some 40 of the 200 Dutch informants tested in 1971 were retested in order to get longitudinal data on language maintenance and loss. The data show surprisingly little loss of proficiency in both Dutch and English over the years. This calls for a revision of the language reversion hypothesis as stated by Clyne in 1981. In the present article the hypothesis is modified to the extent that there seems to be some kind of 'critical threshold' that has to be reached in order to retain the second language. First-language reversion seems to be a common phenomenon among those immigrants who did not reach this threshold, but not among immigrants who did.

90-230 Gold, David L. (U. of Haifa). A sketch of the linguistic situation in Israel today. Language in Society (Cambridge), 18, 3 (1989), 361-88.

The results of the reintroduction and renativisation of Hebrew are highlighted, and some commonly made assumptions about Hebrew and its place in Israeli life examined. The main topics are $(a)$ the debatable equation of an ideal nation-state with a single and exclusive language, $(b)$ the long history of Hebrew as a component of Jewish multilingualism, (c) the Hebraist movement, (d) the extent of its success and its advantages and disadvantages, and $(e)$ linguistic rights in Israel.

\section{0-231 Olshtain, Elite (Tel Aviv U.). Is second-language attrition the reversal of second-language acquisition? Studies in Second Language Acquisition (Bloomington, Ind), 11, 2 (1989), 151-65.}

The study of language attrition, whether it is concerned with first or second languages, focuses on the effects resulting from an individual's reduced use of the attrited language. Such reduction in use can be due to a change in the linguistic environment or to the termination of an instructional programme. In either case, some other language (or languages) is or becomes the dominant one.

The present article reports on a series of studies, all focusing on individual attrition of English as a second language (ESL) in an environment where Hebrew is the dominant language. The predictor variables discussed are age, sociolinguistic features, input variables, and linguistic variables. The attrition process affecting English as a second language in a Hebrew-dominant context seems to exhibit two major trends of change in language use: (a) a greater variability in the application of peripheral and highly marked structural rules, and (b) lower accessibility of specific lexical items. In each of these 
trends one can identify a limited reversal of the acquisition process, particularly with young children (5-8-year-olds) as well as a typological transfer process from the dominant language.

\section{0-232 Sato, Charlene J. (U. of Hawaii at Manoa). A non-standard approach to Standard English. TESOL Quarterly (Washington, DC), 23, 2 (1989), 259-82.}

Recent attempts to establish English-only public policy and legislation reflect declining support for sociolinguistic diversity in the United States. This trend has important consequences in education, not only for speakers of languages other than English, but also for speakers of minority varieties of English. In this article, assimilationist ideology is rejected as a way of legitimising the educational experience of language minority groups. Instead, a pluralist position is adopted, one that views the teaching of standard English as a second dialect (SESD) as 'additive bidialectalism' rather than remediation. The terms 'dialect', 'creole' and 'standard' are discussed with reference to the harmful effects of linguistic prescriptivism. Research in two areas is then reviewed: (a) studies examining differences in varieties and their influence on communication and (b) sociolinguistic work on classroom participation structures involving language minority students. It is concluded that differences in varieties are not trivial and that culturally appropriate modifications to classroom discourse patterns, such as those implemented in a programme for Hawaii Creole English-speaking children, are useful models for other SESD settings.

\section{0-233 Spolsky, Bernard (Bar-Ilan U., Israel). Maori bilingual education and language revitalisation. Journal of Multilingual and Multicultural Development (Clevedon, Avon), 10, 2 (1989), 89-106.}

The attempts at Maori language revival started in the 1970s, at a stage when there were few children still growing up speaking the language. The most important innovation has been the development of pre-school language nests; several thousand children now come to elementary school after a pre-school programme taught entirely or mainly in Maori. There are some bilingual schools; a growing number of elementary schools with Maori immersion in the first one or two years; and some high school programmes. The paper describes a number of these schools, discusses the way that the bilingual programmes define and establish Maori space in the schools, mentions the issue of local and tribal concerns, and argues that there is the basis here for revitalisation of the language.

\section{0-234 Swisher, M. Virginia U. of Pittsburgh) and McKee, David (California State U.). The sociolinguistic situation of natural sign languages. Applied Linguistics (Oxford), 10, 3 (1989), 294-312.}

The study of signed languages can reveal whether or not sociolinguistic phenomena previously observed for spoken languages are general across modalities. In fact, like spoken languages, signed languages exhibit variation related to age, race, sex, and religion, and like other minority languages within majority cultures show effects of language contact (despite the difference of modality between the minority and majority languages). The situation of signed languages as minority languages produces in their users ambivalent attitudes toward both the signed language and the language of the hearing community, parallel to those experienced by speakers of creoles or other minority languages. As with creoles, varieties of signed languages can be viewed as varying along a continuum between the pure form of the signed language and the spoken standard, with the variety used depending on factors such as the hearing status of the interlocutor, the formality of the occasion, and so forth. In its pure form, the signed language is a different language which employs some grammatical mechanisms which are radically different from spoken ones, because of the linguistic use of visual space. For signed languages, unlike spoken ones, schools do not serve as a force for standardisation, since in most countries codes for the standard language are used in education of deaf children, rather than natural sign languages. The use of these codes contributes to lexical variation in the sign languages to some degree, but large-scale invasion of vocabulary items from the majority language is resisted both for cultural reasons and because of constraints governing the formation of signs. 
90-235 Taft, Ronald (Monash U.) and Cahill, Desmond (Phillip Inst. of Tech., Coburg. Victoria, Australia). Mother tongue maintenance in Lebanese immigrant families in Australia. Journal of Multilingual and Multicultural Development (Clevedon. Avon), 10, 2 (1989), 129-43.

Maintenance of mother tongue (L1) by immigrants implies both competence in the language and the use of it. A study was conducted on the maintenance of L1 by 10- to 11-year-old children of Lebanese immigrants in Melbourne. While most of the 62 subjects could speak Lebanese well, few could read or write it. It was found that the children's competence in L1 was largely a function of the literacy level of their parents and their interest in the quality of their children's language, while the actual use of $L 1$ by the children reflected their opportunities to speak it and the necessity for them to do so, rather than their competence in it or their linguistic and ethnic attitudes.

\section{Psycholinguistics}

90-236 Carrithers, Caroline. Syntactic complexity does not necessarily make sentences harder to understand. Journal of Psycholinguistic Research (New York), 18, 1 (1989), 75-88.

Researchers studying language comprehension have assumed that, all else being equal, more complex sentence constructions will take longer to process. However, results from experiments, such as the one presented in this paper, which use reading rates as the dependent measure suggest that it is the interaction of specific types of deep structure representations with their surface structure forms that accounts for fluctuations in readers' on-line processing of various sentence types. In particular, those sentences in which the deep structure direct object immediately precedes the verb in the surface structure sequence are easier for comprehenders to process. These data support a dual, parallel processing model of sentence comprehension in which lexical and morphological/relational information are processed independently.

\section{0-237 Chaney, Carolyn (San Francisco State U., CA). I pledge a legiance tothe} flag: three studies in word segmentation. Applied Psycholinguistics (Cambridge), 10. 3 (1989), 261-81.

Three experimental tasks explored young children's metalinguistic awareness of word boundaries. First, preschool children recited word-by-word pieces which differed in abstractness and familiarity of vocabulary. Second, a teaching task was employed to train and then sample selected items taken from the recited pieces, representing words with cards. The data suggested that several strategies were employed: segment-by-phrase, segment-bysyllable, and segment-by-word. Children were less successful in segmenting the more abstract piece than the concrete one, and they tended to revert to a phrase strategy and/or to change abstract words into more common vocabulary. Error analysis revealed growing awareness of the functors $a$ and the. In a third experiment, preschool and kindergarten children segmented phrases using the functors $a, a n, m y$, or and phrases using phonetically similar embedded syllables (e.g., hold my nose; gold miner). Segmentation scores increased with age; even the $4 \frac{1}{2}$ - to 5 -year-olds were highly successful, segmenting with $60 \%$ accuracy, and by age $6-6 \frac{1}{2}$, they were correctly segmenting $75 \%$ of the phrases. Children who had begun to read performed better overall than their same-age peers who had not. Children were more successful with $m \gamma$, or, and word-medial $a$ than with an and word-initial $a$; embedded syllables tended to be easier than functors, especially for the younger subjects. In conclusion, the years from age $4 \frac{1}{2}$ to $6 \frac{1}{2}$ appear to be a period of vigorous development of word segmentation skills. During this period, children use increasingly complex strategies - first phrasal, then syllabic, and finally a full word strategy - and they demonstrate a growing knowledge of function words as well as content words. Functors vary in difficulty and developmental sequence due to differences in stress, amount of ambiguity with phonetically similar embedded syllables, semantic complexity, and salience of reference to the young child. 


\section{0-238 Felix, Sascha W. (U. of Passau). Universal Grammar in language acquisition. Canadian Journal of Linguistics (Toronto), 33, 4 (1988), 367-93.}

An important concern in language acquisition studies is the nature of the interaction between the innate principles of Universal Grammar and the child's linguistic experience in the language learning process. Two conflicting theories as to the nature of this interaction, characterised as perceptionism and maturation, are discussed. In the former, language development is driven by the child's perception of external evidence. As new data are encountered, the child is forced to restructure his/her innate grammar. Child grammars are thus not considered to violate any principles of Universal Grammar. In contrast, the latter suggests that development is driven primarily by biologically determined mechanisms, and that violations of Universal Grammar are indeed possible. Experimental evidence is cited to provide evidence in favour of this view. The observation that children in early stages of development produce structures which are not permissible in adult languages leads to the suggestion that Universal Grammar principles are not fully active from the beginning of the acquisition process. Acquisition must therefore be seen not as an 'additive' process but as one of 'replacement' whereby earlier grammars are later restructured and supplanted in accordance with a specific schedule of maturation.

\section{0-239 Fernald, Anne (Stanford U.) and others. A cross-language study of} prosodic modifications in mothers' and fathers' speech to preverbal infants. Journal of Child Language (Cambridge), 16, 3 (1989), 477-501.

This study compares the prosodic modifications in mothers' and fathers' speech to preverbal infants in French, Italian, German, Japanese, British English, and American English. At every stage of data collection and analysis, standardised procedures were used to enhance the comparability across data sets that is essential for valid cross-language comparison of the prosodic features of parental speech. In each of the six language groups, five mothers and five fathers were recorded in semistructured home observations while speaking to their infant aged $0 ; 10-1 ; 2$ and to an adult. Speech samples were instrumentally analysed to measure seven prosodic parameters: mean fundamental frequency $\left(f_{0}\right)$, $f_{0}$-minimum, $f_{0}$-maximum, $f_{0}$-range, $f_{0}$-variability, utterance duration, and pause duration. Results showed cross-language consistency in the patterns of prosodic modification used in parental speech to infants. Across languages, both mothers and fathers used higher mean- $f_{0}, f_{0}-$ minimum, and $f_{0}$-maxi- mum, greater $f_{0}$-variability, shorter utterances, and longer pauses in infant-directed speech than in adult-directed speech. Mothers, but not fathers, used a wider $f_{0}$-range in speech to infants. American English parents showed the most extreme prosodic modifications, differing from the other language groups in the extent of intonational exaggeration in speech to infants. These results reveal common patterns in caretaker's use of intonation across languages, which may function developmentally to regulate infant arousal and attention, to communicate affect, and to facilitate speech perception and language comprehension. In addition to providing evidence for possibly universal prosodic features of speech to infants, these results suggest that languagespecific variations are also important, and that the findings of the numerous studies of early language input based on American English are not necessarily generalisable to other cultures.

\section{0-240 Fowler, Carol A. (Dartmouth Coll. and Haskins Labs.). Differential shortening of repeated content words produced in various communicative contexts. Language and Speech (Hampton Hill, Middx), 31, 4 (1988), 307-19.}

Three experiments examined the conditions under which repeated words undergo durational shortening in speech. Previous research showed that repeated content words are shortened in spontaneous speech. One experiment in the present series found no shortening when words are produced in lists. In a second experiment, reductions were observed for the same words produced in meaningful prose. Words preceded by homophones did not undergo shortening. The findings suggest that shortenings reflect talkers' exploitation of a word's redundancy in the context of a discourse. A final experiment found more shortening of content words produced in a communicative context than in the same discourse, transcribed and read into a microphone. Possibly, the tendency to shorten is increased by the presence of a listener; alternatively, it may reflect the slower speech rate characteristic of spontaneous as compared to read speech. 
90-241 Gibbs, Raymond W. Jr., and others (U. of California, Santa Cruz). How to kick the bucket and not decompose: analysability and idiom processing. Journal of Memory and Language 28, 5 (1989), 576-93.

Idiomatic phrases differ in their degree of analysability. Some idioms are highly decomposable with the meanings of their parts contributing independently to their overall figurative meanings (e.g., pop the question can be decomposed into pop meaning 'suddenly make' and the question referring to 'a marriage proposal'). Other idioms are nondecomposable because it is difficult to see any relation between a phrase's individual components and the idiom's figurative meaning (e.g., the parts of kick the bucket do not independently contribute to the figurative meaning of the phrase 'to die'). The present studies investigated the role of analysability or semantic decomposition in idiom processing. It was expected that nondecomposable idioms should be processed more quickly than decomposable phrases because expressions such as kick the bucket are lexicalised and should be easier to access from the mental lexicon. However, Experiment 1 showed that nondecomposable idioms were processed more slowly than analysable idiom phrases. Experiment 2 and 3 indicated that previous research demonstrating a processing advantage for syntactically frozen idioms was due to their degree of semantic decomposition. The results of these experiments suggest that idioms are initially processed in a compositional manner similar to understanding of more literal language. However, people still do not necessarily analyse the literal meanings of idioms during understanding of these figurative phrases.

\section{0-242 Harris, Roy. How does writing restructure thought? Language and Communication (Oxford). 9, 2/3 (1989), 99-106.}

Referring mainly to the ancient Greek context, the author rejects two popular views about how writing affects thought, and offers a third. The first rejected view is that the alphabet is the crucial invention and is superior to non-alphabetic writing systems because it implies a capacity for phonemic analysis; in fact the Greek and Roman systems are not phonemic and ancient Greek linguists do not show this capacity. The second view is that writing reduces rote memory load and frees minds for other tasks; in fact not memorising information may entail impoverishment, and in any case writing imposes its own memory load.

The real advantage of writing is that people are enabled to distinguish between sentences and utterances, creating between them an 'autoglottic space' for activities such as logic and grammar. They can consider a proposition independent of its 'sponsor', a particular person asserting it at a particular time. Only thus does it become possible to ask Socratic questions such as 'What is justice?'

\section{0-243 Johnson, Janice (York U., Ontario). Factors related to cross-language} transfer and metaphor interpretation in bilingual children. Applied Psycholinguistics (New York), 10, 2 (1989), 157-77.

The study examines factors underlying crosslanguage transfer in bilingual children; the main focus is on a measure of metaphor interpretation. Subjects were Spanish-English children ranging in age from 7 to 12 years. Measures were obtained for non-verbal mental capacity, metaphor interpretation, verbal-conceptual repertoire, and linguistic proficiency in English and Spanish. Using a previously validated procedure, subjects' metaphor interpretations were scored for cognitive complexity. In both languages, metaphor score was higher in older than in younger children. Correlational analyses indicated that level of metaphor interpretation was most strongly related to cognitive-developmental variables that are interdependent across languages, that is, non-verbal mental capacity and verbal-conceptual repertoire. Variables that measure specific proficiency in a language were less strongly related to level of metaphor interpretation, and did not exhibit crosslanguage correlations. This pattern was clearly seen in results of exploratory factor analyses. The role of cognitive versus linguistic factors in metaphor development is discussed, as is the issue of interdependence versus independence across first and second languages. 
90-244 Kilborn, Kerry (Max-Planck-Institut für Psycholinguistik, Nijmegen. The Netherlands). Sentence processing in a second language: the timing of transfer Language and Speech (Hampton Hill, Middx), 32, 1 (1989), 1-23.

Traditional approaches to second-language performance have typically focused on form-related aspects of transfer, without addressing the issue of real-time constraints inherent in the comprehension process. The current study uses an on-line sentence comprehension paradigm to investigate how and when three different cues (word order, noun-verb agreement morphology, animacy relations) to thematic role assignment interact during comprehension. Results indicate that monolingual English speakers depend on word order, often making thematic role assignments immediately after the first noun is encountered, and generally do not attend to morphological information. In contrast, native German speakers depend on morphological cues in their native language, delaying responses until all potential cues are in. When the same subjects perform the task in their second language, English, a similar result is observed, indicating that Germanbased processing strategies are transferred to on-line processing in the second language. The findings are related to a psycholinguistic model of language performance, the Competition Model, proposed by Bates and MacWhinney.

\section{0-245 Lemmon, Christian R. (U. of Mississippi) and Goggin, Judith P. (U.} of Texas, El Paso). The measurement of bilingualism and its relationship to cognitive ability. Applied Psycholinguistics (New York), 10, 2 (1989), 133-55.

The present experiments explored various measures of English and Spanish language ability and compared monolingual and bilingual subjects on tests of cognitive skill. Language ability was assessed in Experiment 1. These measures were found to be highly correlated with each other, with at least two factors needed to describe the associations among the tests in each language. In Experiment 2, subjects were given tests of cognitive skills. To be included in this study, all subjects were required to show adequate understanding of English and were divided into monolingual and bilingual groups on the basis of their Spanish abilities. Monolinguals scored higher than bilinguals on most of the measures of cognitive skill, but subsequent comparisons of the monolinguals with high and low bilingual subgroups suggested that the differences were attributable to those subjects characterised as low bilinguals.

90-246 Leonard, Laurence B. (Purdue U., IN). Language learnability and specific language impairment in children. Applied Psycholinguistics (New York), 10, 2 (1989). 179-202.

Theories of language learnability have focused on 'normal' language development, but there is a group of children, termed 'specifically languageimpaired,' for whom these theories are also appropriate. These children present an interesting learnability problem because they develop language slowly, the intermediate points in their development differ in certain respects from the usual develop- mental stages, and they do not always achieve the adult level of language functioning. In this article, specifically language-impaired children are treated as normal learners dealing with an input that is distorted in principled ways. When the children are viewed from this perspective, Pinker's theory can account for many of the features of their language.

\section{0-247 Macaruso, Paul and others ( $U$. of Connecticut). Comprehension of temporal terms by good and poor readers. Language and Speech (Hampton Hill, Middx), 32, 1 (1989), 45-67.}

Poor beginning readers often have difficulty comprehending spoken sentences with complex syntactic structures. This study attempts to identify the reasons for this difficulty. Second-grade good and poor readers were tested for comprehension of spoken sentences containing the temporal terms before and after. Processing load was varied systematically while holding syntax constant in an effort to determine whether processing factors contribute to poor readers' comprehension problems, or whether poor readers are simply lacking the structural knowledge required to understand sentences containing tem- 
poral terms. The poor readers' high level of performance under conditions of reduced processing demands suggests that their misinterpretations in spoken language understanding may be due, in large part, to limitations in verbal working memory.

\section{0-248 MacLaren, Richard I. (U. of Toronto). The distinction between linguistic awareness and metalinguistic consciousness: an applied perspective. Rassegna Italiana di Linguistica Applicata (Rome), 21, 1/2 (1989), 5-18.}

A preliminary definition of linguistic awareness and metalinguistic consciousness is proposed. Awareness of language involves, to some degree, a metatheory, possibly including a metalanguage about language rules and conventions. Metalinguistic consciousness is a deeper, more all-encompassing notion. It too includes a metatheory, but this is a language for talking about the relation of self to language rules and conventions. Is the distinction between linguistic awareness and metalinguistic consciousness useful as far as an integrated or applied psycholinguistics goes? The approaches of the developmental psycholinguist and the applied psycholinguist are very different. The objectives of the former are theory generation and testing using empirical methods, whereas the latter's research involves pedagogical goals. Developmentalists study primarily first language acquisition, and applied researchers can study first, second and third language learning and the interactions among these as they relate to language teaching. Both kinds of psycholinguists are interested in the development of 'metalinguistic awareness' of all kinds. To this end, developmentalists have studied children's understanding of syntax or grammar and found that (slightly advanced) two-year-olds could make appropriate corrections for grammaticality, but offered no explanations for why these should be made. They also tested six-to-eight-year-olds' understanding of ambiguity and metaphor.

Applied psycholinguists can point to distinct stages in the development of metalinguistic awareness, but it is likely that not all of these stages apply to the second-language learner. Maturational factors, automaticity of functioning, contextual and motivational factors all have different effects on first and second language learning. Titone has proposed a hierarchical model governing language learning, and including ego-dynamic, strategic and tactical levels. The ego-dynamic level assumes the existence of a directing, unifying self which can adjust strategic and tactical operations according to situational context. The ego-dynamic level stresses the importance of affective factors, and gives priority to an understanding of communicative intentions, which are crucial to metalinguistic awareness. It is hoped this model may be tested empirically on secondlanguage learners.

\section{0-249 Morgan, James L. and Travis, Lisa L. (U. of Minnesota). Limits on} negative information in language input. Journal of Child Language (Cambridge), 16, 3 (1989), 531-52.

It has recently been suggested that certain types of parental repetitions and clarification questions may provide children with subtle cues to their grammatical errors. This possibility was further investigated by examining parental responses to inflectional over-regularisations and wh-question auxiliary-verb omission errors in the sets of transcripts from Adam, Eve and Sarah. These errors were chosen because they are exemplars of overgeneralisation, the type of mistake for which negative information is, in theory, most critically needed. Expansions and Clarification Questions occurred more often following ill-formed utterances in Adam's and Eve's input, but not in Sarah's. However, these corrective responses formed only a small proportion of all adult responses following Adam's and Eve's grammatical errors. Moreover, corrective responses appear to drop out of children's input while they continue to make overgeneralisation errors. Whereas negative feedback may occasionally be available, in the light of these findings the contention that language input generally incorporates negative information appears to be unfounded.

90-250 Oksaar, Els (Hamburg U., FRG.). Psycholinguistic aspects of bilingualism. Journal of Multilingual and Multicultural Development (Clevedon, Avon), 10, 1 (1989). 33-45.

Bilingualism, not monolingualism, is the norm, yet linguists continue to study bilingualism as if the reverse were true, and school systems in most European countries are based on the same as- 
sumption. No adequate criteria exist for assessing bilingual competence. A working definition is proposed: the ability of an individual to use two languages in most situations and to switch from one to the other where necessary. Past studies of early bilingualism emphasised the disadvantages for the child. More recent studies, however, stress the positive benefits, suggesting that the disadvantages may be environmentally determined, arising from a conflict of cultures. Adults, too, can achieve bilingualism. Native-like pronunciation is not everything. With adults, motivation appears to be the determining factor.

Bilingualism presupposes of necessity a degree of biculturalism. Examples are cited from England, Germany, Scandinavia, the Baltic States, Japan, Korea, S.E. Asia, the Philippines and the USA to illustrate how communication problems for bilinguals may be the consequence of differing modes of interaction, cultural values and assumptions.

\section{0-251 Rubin, Hyla (U. of Connecticut and Haskins Labs.). Morphological knowledge and early writing ability. Language and Speech (Hampton Hill, Middx). 31, 4 (1988), 337-55.}

This study assessed the morphological knowledge of kindergarteners and first graders in relation to their early writing ability. Morphological knowledge was investigated because, in order to write, children need to understand that words are composed of morphemes and phonemes, and because poor writers have particular difficulty with inflected forms of words. Kindergarteners and first graders were grouped by their implicit understanding of morphology and were given tests of dictated spelling and morphological analysis. First graders with poor implicit morphological knowledge omitted more inflectional morphemes in writing and were less able to identify base morphemes in spoken words than kindergarteners and first graders with higher levels of implicit morphological knowledge. The results demonstrate the importance of morphological knowledge in the development of written language proficiency.

\section{0-252 Swisher, M. Virginia (U. of Pittsburgh). The language-learning situation of deaf students. TESOL Quarterly (Washington. DC), 23, 2 (1989), 239-57.}

Deaf children often have major difficulty learning the language of their parents, who in the majority of cases are hearing. The principal reason for these problems is limitation of linguistic input reaching the children: the hearing loss itself acts as a drastic filter on the linguistic data, and information obtained from aided residual hearing, as well as from visual sources such as lipreading and signed representations of spoken language, is typically fragmentary. In addition to the limitations of input, the very difficulty of the task of learning an auditory language with severely restricted information is likely to lead to loss of motivation. Another complicating factor is language attitudes and the fact that the deaf community uses a visual-spatial language, American Sign Language (ASL), which deaf people acquire without effort and which provides a focus for cultural solidarity. Attitudes towards ASL are complicated by its identity as a minority language in a majority culture, whose standard language influences it to some extent. Attitudes toward English are complicated by the fact that the learning of English is imposed by an educational establishment run by hearing people and that ASL is not used as a language of instruction.

\section{0-253 Watson, Rita (U. of British Columbia). Literate discourse and cognitive organisation: some relations between parents' talk and 3-year-olds' thought. Applied Psycholinguistics (New York), 10, 2 (1989), 221-36.}

Implicit in much work on literate discourse and its consequences is the question of what relation exists between forms of discourse and cognitive organisation. The focus of this article is the relation between specific features of literate discourse and paradigmatic organisation in children's thought. Nineteen parent-child dyads were videotaped during bookreading when the child was $2 \frac{1}{2}$ years old. Three levels of object labels and reference to propositional attitudes were coded in parents' talk during bookreading episodes with their children. Three measures of paradigmatic organisation in the child's thought were obtained at age $3 \frac{1}{2}$. The features of parents' talk were then correlated with measures of the child's thought. A significant correlation was found between superordinate level labels in parents' talk and all three measures of children's paradigmatic organisation, but basic and subordinate level labels 
were not correlated. Parents' use of cognitive verbs and verbs referring to labelling and interpretation were also correlated with children's paradigmatic organisation. The results are interpreted as indicating situation-specific organisational preferences in talk and thought.

\section{Pragmatics}

\section{0-254 Andrews, Barry J. (Macquarie U., Australia). Terminating devices in spoken French. IRAL (Heidelberg, FRG), 27, 3 (1989), 193-216.}

This study describes how one group of articulating signals, the terminators, functions in contemporary spoken French. The terminators are discourse connectors that in the first place signal to the listener that the speaker has finished his utterance, or a part thereof; they can also be a signal to the listener indicating that some sort of reaction is expected from him, or that it is an appropriate time for him to speak in his turn. Apart from classifying the terminators in three main groups and examining the main members of these groups, the article comments at some length on the role played by intonation, both in relation to the terminator itself and to the section of the utterance that immediately precedes the terminator. In all speech, of course, the overall meaning, both cognitive and affective, is the result of an amalgam of a number of factors, one of the most important of which is intonation. One of the aims is to show that this is equally the case with the terminators, where the overall meaning of 'terminating signal' is created from a combination of the inherent meaning, position in the utterance, and the associated intonation patterns.

\section{0-255 Bhatia, V. K. (U. of Singapore). Legislative writing: a case of neglect in EA/OLP courses. English for Specific Purposes (New York), 8, 3 (1989), 223-38.}

This paper begins by establishing the need to prioritise language skills in legal education and then gives a brief overview of the English for Academic/Occupational Legal Purposes (EA/OLP) situation, concentrating particularly on the recent preoccupation with the use of simplified and abridged versions of legal cases in many of the available EA/OLP programmes to the neglect of legislative use of language. It then argues for a need to link the study of cases with legislative writing on theoretical as well as practical grounds. In principle, cases are attempts to interpret the facts of the outside world in terms of general abstract principles known to specialists in law as ratio decidendi, whereas the essence of legislative interpretation lies in an attempt to understand the general abstract rules which in themselves are nothing but attempts to account for the facts of the world. This is reflected not only in the discourse and cognitive structuring in the two genres but also in the tasks that are normally assigned to law students in their academic and professional courses. The two processes, therefore are complementary to each other and any attempt to neglect one at the cost of the other is likely to leave the learners somewhat less than proficient in the use of legal language in the advancement of their professional career. Worse still, it may create in them a kind of awe about legislative writing which they may find difficult to get over for the rest of their careers.

\section{0-256 Gibbs, Raymond W., Jr. (U. of California, Santa Cruz) and others. Common ground in asking and understanding questions. Language and Speech (Hampton Hill. Middx), 31, 4 (1988), 321-35.}

An important part of the context speakers and listeners use in conversation is their 'common ground'-their mutual knowledge, beliefs, and assumptions. This paper reports the findings of two experiments that investigated the role of common ground information in asking and understanding questions. Subjects read stories containing conversations that depicted different degrees of common ground information between the characters who served as speakers and addressees. The subjects were asked in Experiment 1 to select the question from a set of alternatives that the speaker would most likely say in a given context. Experiment 2 examined the time it took subjects to understand different questions posed by the speaker given the presence of different types of common ground between the speaker and addressee. The results of the first study indicated that subjects preferred to ask questions which adequately specified the degree of common ground between speakers and addressees that was depicted in the story contexts. Experiment 2 demonstrated that people take less time to com- 
prehend questions that are congruent with the common ground information held by speakers and listeners in a discourse situation. These data highlight the importance of common ground as constituting the context for asking and understanding questions. More generally, these studies provide additional experimental support for collaborative models of language use.

90-257 Hodge, Bob (Murdoch U., Perth. Australia). National character and the discursive process: a study of transformations in popular metatexts. Journal of Pragmatics (Amsterdam), 13, 3 (1989), 427-44.

National stereotypes are normally treated as instances of crude prejudice, regrettable but too obvious in function and content to require careful analysis. This article draws on some early work of Gregory Bateson to argue that these stereotypes in fact encode core knowledge for members of the community, in a form that excludes outsiders. This knowledge concerns primary bi-polar constructs and transformational capacities that organise discursive forms in the community. It is conveyed through a set of metatexts with a wide circulation. The article argues the case with reference to Australian texts (popular literature, TV commercials, fiction) and the Australian national stereotype.

\section{0-258 May, John D. Questions as suggestions: the pragmatics of interrogative speech. Language and Communication (Oxford), 9, 4 (1989), 227-43.}

In asking questions we also convey suggestions and invite conclusions. It is possible to discern patterned associations between the questions asked and suggestions made. The aim of this paper is to provide a comprehensive account of those suggestions conveyed by interrogatives. These are characterised as types of 'nudges', some of which appear to be universal. For example, in asking a question we are suggesting that the question itself is intelligible, salient, answerable, and that the respondent is capable of answering.

Particular suggestions conveyed depend chiefly on the type of question posed and on the communicative situation. Some of these are discussed with reference to notions of feasibility, existence, non-existence, viability and propriety [examples with discussion]. These are seen within the broader framework of the rhetorical function of questions, which is, in many cases, to encourage respondents to adopt preferred responses. In this connection, trick questions are discussed: these nudge addressees in the direction of accepting a suggestion which ought to be rejected and thereby a conclusion which is not warranted.

\section{0-259 Robinson, Peter J. (U. of Pittsburgh, PA). Procedural vocabulary and language learning. Journal of Pragmatics (Amsterdam), 13, 4 (1989), 523-46.}

In this paper the author considers the role that a 'core' vocabulary might play in language learning and teaching. Such words, which are highly context dependent, provide learners with a strategic resource for overcoming breakdowns in communication, particularly the negotiation of the meanings of more specific technical terms. As such these words are of 'procedural' value to learners. The author looks first at the problem of identifying what such procedural words are. He then looks at aspects of the semantic and pragmatic competencies which lead to procedural 'ability' in the use of such words in discourse, and then at how procedures involving the use of these words are realised on the interactional and transactional planes of discourse. He concludes with a further look at the structural properties of such words, and with recommendations for the role they should occupy in language teaching and learning. 